\section{Rulers and the ruled-some reflections on the NHS}

DeAr Sirs

Morale, that most delicate of hot-house plants, is not at its best in our Unit. It shows distinct signs of wilt. We are short of nurses; a combination of myopic training policies and high local house prices has ensured this. The regrading exercise has been conducted clumsily even by the exacting national standards of clumsiness. We are being exhorted by all and sundry to spend less. The latest assault is called 'Cost Improvement'; in an already overstretched service we are required to save $1 \%$ of revenue expenditure each year so that money will be available for 'service development' - presumably this will consist of a partial restoration of the services that were cut to obtain the cost improvement.

As always happens in such circumstances, some of us have been driven to the consolations of philosophy. St Augustine wrote ever more feverishly as the barbarians got closer to Hippo. Our thoughts may be trivial and ephemeral compared to his, but kind readers will attribute this to the fact that he had a more ferocious class of barbarian to stimulate him. Ours are a somewhat motley crew led by a small group of supermarket-style managers. Rape and pillage is not their forte, but nevertheless one fears arriving at work one day to find patients and colleagues alike stamped with sell-by dates. Be that as it may, my main contribution to the philosophical movement has been to come up with a general law.

It was inspired by observation of local car-parking practices. We have an overcrowded site and parking is difficult. A new barrier park was recently opened and tickets for it issued. Quite junior administrative staff had no problem getting theirs. Senior ward sisters had a different experience and must drive about disconsolately when trying to get to work, like storm-tossed migrating birds hoping to find a ship on which to rest. Generalise from this observation, and you have the law: "In the NHS, an employee's importance bears an inverse relationship to the usefulness of the work that he does".

One cannot claim that the idea is original. It is implicit in Gilbert's song in The Mikado which lists the important people who would not be missed. Ward sisters would certainly be missed more than junior administrators; so would cleaners compared, dare one say it, to nursing officers; so, even more heretical to propose, would ward doctors relative to chairmen of divisions.

Like the poor, the useful work of treating and comforting patients, teaching and research is always with us. Everyone knows that there must be some rationing of resources since the needs are almost infinite. It is a mistake, though, to exalt the rationers above all other workers and even more of a mistake to convert those who should be doing or facilitating useful work into rationers. Lots of perfectly good clinicians and helpful administrators have been suborned into this role over recent years. They have been persuaded to become NHS hatchet men, necessary to the service in much the same sort of way as hangmen were necessary to the judiciary a hundred years ago. The Government seems determined to turn yet more of us into rationers by direct financial incentives to GPs and a combination of threats and manipulation of merit awards in the case of consultants. It is therefore most important that we clearly understand the role. Hatchet men are necessary, but surely too uncouth to be received in polite company. See them for what they are and they will lose some of their power.

In the NHS, doctors must work for two masters, patients and the Government. This is not inherently any more difficult than the servitude which doctors have endured in other times and places to Mammon or to God. Indeed, until the recent collapse of consensus politics it was an easier yoke. Now that it has been made more difficult for us, we shall need to start thinking about and debating topics which had become mercifully unfamiliar over most of the NHS's lifetime.

\section{Royal South Hants Hospital}

C. M. H. NUNN

\section{Southampton}

\section{Liaison psychiatry}

\section{DeAR SirS}

I note that the expression "liaison psychiatry" has finally crossed the Atlantic (Guidelines for Training in Liaison Psychiatry, Psychiatric Bulletin, September 1988, 12, 389-390).

In the course of my practice, I frequently had to call in a surgeon to take out an appendix or call in a cardiologist, an ENT surgeon or a dermatologist to see and treat a psychiatric patient in my care. I have never heard any of them calling themselves a "liaison abdominal surgeon", a "liaison cardiologist", etc.

I am not aware that any of the other Colleges have considered establishing a sub-specialty or special training for liaison surgeons, liaison cardiologists, etc.

Are we psychiatrists once again, two blocks ahead of everyone else? Have the other doctors missed out on something important? I know we carry a lot of silly jargon in our specialty knapsack, even without this liaison stuff; but should we keep adding to this?

\section{Clarke Institute of Psychiatry \\ 250 College Street, Toronto \\ Ontario, Canada}

J. HOENIG 